This item was submitted to Loughborough's Research Repository by the author.

Items in Figshare are protected by copyright, with all rights reserved, unless otherwise indicated.

\title{
Long-term stability of droplet production by microchannel (step) emulsification in microfluidic silicon chips with large number of terraced microchannels
}

\section{PLEASE CITE THE PUBLISHED VERSION}

https://doi.org/10.1016/j.cej.2017.09.141

\section{PUBLISHER}

(C) Elsevier

\section{VERSION}

AM (Accepted Manuscript)

\section{PUBLISHER STATEMENT}

This work is made available according to the conditions of the Creative Commons Attribution-NonCommercialNoDerivatives 4.0 International (CC BY-NC-ND 4.0) licence. Full details of this licence are available at: https://creativecommons.org/licenses/by-nc-nd/4.0/

\section{LICENCE}

CC BY-NC-ND 4.0

\section{REPOSITORY RECORD}

Vladisavljevic, Goran, Ekanem E. Ekanem, Zilin Zhang, Nauman Khalid, Isao Kobayashi, and Mitsutoshi Nakajima. 2017. "Long-term Stability of Droplet Production by Microchannel (step) Emulsification in Microfluidic Silicon Chips with Large Number of Terraced Microchannels". figshare.

https://hdl.handle.net/2134/26674. 


\section{Long-term stability of droplet production by microchannel (step) emulsification in microfluidic silicon chips with large number of terraced microchannels}

Goran T. Vladisavljevića*, Ekanem E. Ekanem ${ }^{\mathrm{a}}$, Zilin Zhang, Nauman Khalid $^{\mathrm{b}, \mathrm{c}, \mathrm{d}}$, Isao Kobayashi $^{\mathrm{e}}$, Mitsutoshi Nakajima ${ }^{\mathrm{d}, \mathrm{e}}$

${ }^{a}$ Chemical Engineering Department, Loughborough University, Loughborough, Leicestershire LE11 3TU, United Kingdom

${ }^{b}$ School of Food and Agricultural Sciences, University of Management and Technology, Lahore, Pakistan

${ }^{c}$ Centre for Chemistry and Biotechnology, School of Life and Environmental Sciences, Deakin University, Waurn Ponds, Australia

${ }^{d}$ Faculty of Life and Environmental Sciences, University of Tsukuba, 1-1-1 Tennoudai, Tsukuba, Ibaraki 305-8572, Japan

${ }^{e}$ Food Research Institute, NARO, 2-1-12 Kannondai, Tsukuba, Ibaraki 305-8642, Japan

*Corresponding author's address: Department of Chemical Engineering, Loughborough University, Loughborough, LE11 3TU, United Kingdom.

Phone number +441509222518; fax number +441509223923; email:

g.vladisavljevic@lboro.ac.uk 


\begin{abstract}
A long-term production stability of oil-in-water emulsions by microchannel (step) emulsification was investigated using two cross flow silicon chips consisting of 540 or 1,850 microchannels fabricated on 10 parallel terraces. Each terrace was $9.54 \mathrm{~mm}$ long and consisted of 54 channels with a depth of $5 \mu \mathrm{m}$ and a width of $18 \mu \mathrm{m}$ (chip 1) or 185 channels with a depth of $4 \mu \mathrm{m}$ and a width of $8 \mu \mathrm{m}$ (chip 2). The dispersed phase was a mixture of $2 \mathrm{wt} \%$ polycaprolactone (PCL) and $1 \mathrm{wt} \%$ poly(d,l-lactic) acid (PLA) dissolved in dichloromethane and the continuous phase was 2 wt\% poly(vinyl alcohol). After solvent evaporation, the droplets were transformed into highly uniform composite polymer particles with an average diameter of 8.8 or $4.9 \mu \mathrm{m}$. The percentages of active channels, droplet sizes and droplet generation frequencies at individual terraces were investigated in both chips to reveal any flow maldistribution. After $6 \mathrm{~h}$ of production in chip 1 , overall $95 \%$ of the channels produced droplets and the percentage of active channels on each terrace was at least $91 \%$. The percentage of active channels decreased by decreasing the size of the channels. The mean droplet size varied negligibly across individual terraces over $7 \mathrm{~h}$. Slightly higher droplet generation frequencies and smaller percentages of active channels were observed at central terraces. The droplet generation frequencies at the channels located close to each other were similar, indicating that droplet formation dynamics was coupled. The droplet size was not affected by the dispersed phase flow rate.
\end{abstract}

Keywords: Microchannel emulsification; Step emulsification; Microfluidic scale-up; Composite polymer microparticles; Synthetic biodegradable polymers; Poly(d,l-lactic) acid 


\section{Graphical Abstract}
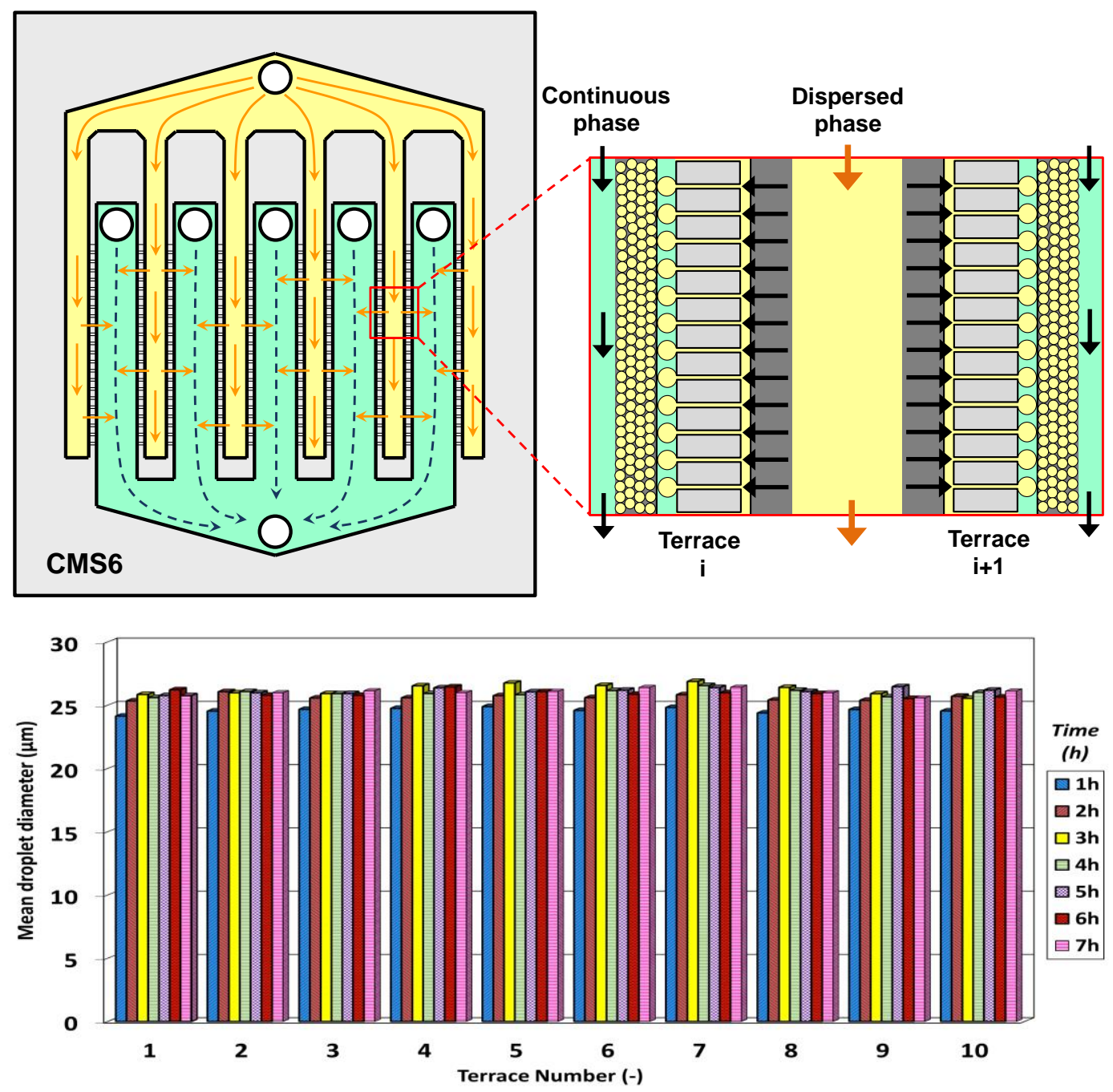

\section{Highlights}

- Production of O/W emulsion by microchannel (step) emulsification was stable over 7h.

- The mean droplet size varied negligibly over time and between different terraces.

- After 6 h production in chip 1, at least $91 \%$ of channels were active on each terrace.

- The CV of droplet sizes on each terrace in chip 1 was between $1.2 \%$ and $2.1 \%$.

- Droplets were solidified into highly uniform composite PLA/PCL microparticles. 


\section{Introduction}

Microfluidic emulsification devices offer a superior control over the size, shape, composition and morphology of droplets $[1,3]$ and the ability to generate monodispersed droplet populations. According to the standards of the National Institute of Standards and Technology (NIST), "a particle size distribution may be considered monodisperse if at least $90 \%$ of the distribution lies within $5 \%$ of the median size" [4], indicating that the span of the size distribution must be $\left(d_{95}-\right.$ $\left.d_{0.05}\right) / d_{50} \leq 0.05$. For the normal distribution, $90 \%$ of the particle sizes lie within 1.64 standard deviations from the mean and thus, $1.64 \sigma \leq 0.05 d_{a v}$. Therefore, the condition for monodispersed size distribution becomes $\sigma / d_{a v} \leq 0.03$ or $C V \leq 3 \%$, where $\sigma$ and $C V$ are the standard deviation and the coefficient of variation of particle sizes, and $d_{a v}$ is the mean particle size. Monodispersed droplets find applications in the synthesis of functional microparticles [5], molecular detection [6], drug discovery, transcriptomics [7], single cell analysis and sorting [8], etc. The most common microfluidic drop generators are T-junctions and flow focusing nozzles [2,9]. Drop pinch-off in both geometries is induced by shear stress at the liquid-liquid interface, implying that the drop size is highly sensitive to fluid flow rates. As a result, small flow rate fluctuations can result in highly polydispersed droplets due to shear force variations [10], making parallelisation of flow focusing nozzles and $\mathrm{T}$ junctions challenging [11].

A single T-junction or flow focusing nozzle can produce droplets at a rate of tens to hundreds of microliters per minute, which is several orders of magnitude below the throughputs needed for industrial applications [12]. Parallelisation of these drop makers typically requires multilayer microfluidic devices with a network of distribution and collection channels to supply the feed 
liquids to each of the drop generators and to collect the formed droplets from all of them [13-15]. Multilayer devices are prone to leakage when operated at the high pressures necessary for high throughput droplet production. In addition, any misalignment between the layers or inappropriate design of channel networks can cause non-uniform flow distribution, resulting in polydisperse droplets [16]. The design of parallelized flow focusing devices is additionally complicated due to requirement to supply both the inner and outer fluid through each nozzle.

A promising approach to simplify the design of microfluidic drop generators and to avoid unwanted polydispersity arising from fluctuations of fluid flow rates is to utilize the concept of step emulsification or "microchannel emulsification", developed by Nakajima et al. [17]. In step emulsification, drops are formed when an interface between two immiscible fluids is subjected to a step change in the height of a microchannel, e.g. when a fluid is injected through a long and shallow microchannel into a deep reservoir, "the well", containing a second immiscible fluid, resulting in curvature imbalance along the interface. In contrast to standard $\mathrm{T}$ junctions and flowfocusing devices, droplets detach from the shallow channel into the well without the need for an external force. The driving force is the sudden drop in the Laplace pressure experienced by the dispersed phase as it passes over the step [18-19]. By adding a constriction with a set of bypasses [20] or a wide plateau ("the terrace") [17] to the end of the shallow channel that slows down the fluid and establishes quasi-static flow with negligible inertial effects, the flow rate of the inner fluid into the forming drop can be decoupled from the applied fluid flow rates [19, 21]. These flow conditions occur in the interfacial tension force dominant regime below the critical capillary number, causing the resultant droplet size to depend only on the channel geometry [22-24]. 
Step emulsification devices with multiple arrays of grooved horizontal channels [17] or vertical straight-through channels [25] have been designed and investigated in Nakajima Lab [2]. The size of the generated droplets ranged from $1 \mu \mathrm{m}$ [26] to more than $1 \mathrm{~mm}$ [27] and the droplet production rate reached $1,400 \mathrm{~mL} \mathrm{~h}^{-1}$ for the dispersed phase viscosity of $2.7 \mathrm{mPa}$ s and the droplet size of 87 $\mu \mathrm{m}$, with $C V \approx 2 \%$ [28]. In the firstly developed dead-end chip, the grooves and terraces were fabricated along the four sides of a square silicon plate and the droplets were formed within a stagnant continuous phase [17]. Dead-end chips are limited to four terraces and they suffer from slow, buoyancy-driven removal of droplets from the device. The higher droplet production rates can be achieved in cross flow chips, because more than four terraces can be fabricated on a single chip and the droplets can be promptly removed from the chip by cross flowing continuous phase. There is a separate MC array and terrace along each side of the crossflow channel and thus, the total number of terraces and MC arrays in cross flow chips is twice the number of cross flow channels. The first cross flow chip consisted of one cross flow channel with two terraces and 22 channels $(11 \times 2)[29]$ and the largest chip had 7 cross flow channels with 14 terraces and overall 11,900 channels $(850 \times 14)[30]$.

The main challenge in microfluidic devices composed of a large number of droplet generators is to achieve a consistent and narrow droplet size distribution from all drop makers over as long a period as possible. A continuous production of monodispersed oil-in-water $(\mathrm{O} / \mathrm{W})$ emulsions by microchannel emulsification over a period of 7 days was demonstrated by Zhang et al. [31]. A long-term production stability is a key requirement to make the process applicable on industrial scale. Zhang et al.'s work was done using model emulsions composed of soybean oil and lowmolecular weight surfactants (Tween 20 and SDS). They only measured overall droplet size 
distribution and overall mean droplet size as a function of time, while droplet size distribution and mean droplet size from individual terraces were not measured. In this work, a long-term production of $\mathrm{O} / \mathrm{W}$ emulsions was investigated using the dispersed phase composed of a binary blend of biodegradable synthetic polymers dissolved in dichloromethane (DCM). For the first time, the mean droplet size and the coefficient of variation were measured for each terrace separately to establish whether the chip can generate uniform droplets consistently from all 10 terraces. In addition, the percentage of active channels was measured as a function of time for all 10 terraces and the location of inactive channels was monitored to reveal any malfunctioning terrace or any regions in the chip with low droplet productivity. It was more challenging to sustain a long-term generation of uniform droplets in this work than in the previous study [31], due to very low viscosity of DCM compared to that of soybean oil, the presence of dissolved polymers in the dispersed phase that can be deposited on the channel walls and high aqueous solubility of DCM $\left(20 \mathrm{~g} / \mathrm{L}\right.$ at $\left.20{ }^{\circ} \mathrm{C}\right)$, as compared to almost complete insolubility of soybean oil in water.

This study confirms that very uniform distribution of dispersed phase can be achieved in the chip and sustain for long periods of time, despite large number of drop generation units and complicated chip geometry. Furthermore, the generated droplets can be solidified into highly uniform biodegradable microparticles, which can be used as carriers for intravenous drug delivery.

\section{Materials and Methods}

\subsection{Materials}


Synthetic biodegradable polymers, poly (d,l-lactic) acid (PLA, IngeoTM 4060D, $\mathrm{M}_{\mathrm{w}}=89,000 \mathrm{~g}$ $\mathrm{mol}^{-1}$, NatureWorks LLC, USA) and polycaprolactone (PCL) $\left(\mathrm{M}_{\mathrm{w}}=14,000 \mathrm{~g} \mathrm{~mol}^{-1}\right.$, Sigma Aldrich, UK), were used to form composite microspheres. The dispersed phase was a mixture of $2 \mathrm{wt} \%$ PLA and $1 \mathrm{wt} \%$ PCL dissolved in DCM (Fisher Scientific, UK). Trace amounts of two fluorescent dyes, Rhodamine 6G (Rh6G) and Nile Red (Sigma-Aldrich, UK), were added to the organic phase to improve the interface clarity during drop generation and as an indicator of resulting morphology of the particles formed after solvent evaporation. The continuous phase was $1.5 \mathrm{wt} \%$ poly(vinyl alcohol) (PVA) ( $\mathrm{M}_{\mathrm{w}}=13,000-23,000 \mathrm{~g} \mathrm{~mol}^{-1}, 87-89 \%$ hydrolysed, Sigma Aldrich, UK) dissolved in Milli-Q water.

\subsection{Microchannel (MC) Chips}

Two single crystal silicon microchannel (MC) chips (CMS6 type,) with the same geometry (Figure 1), but different size and number of MCs (Table 1) were used in this study. The chips are designed by NFRI, NARO, Tsukuba and EP Tech Co. Ltd., commercialized by EP Tech, Co., Ltd., and microfabricated by photolithography and anisotropic wet etching by Hitachi Power Semiconductor Device, Ltd., Hitachi, Japan.

\section{Figure 1}

CMS6 chips have cross-sectional dimensions of $28 \mathrm{~mm} \times 25 \mathrm{~mm}$ and a thickness of $0.5 \mathrm{~mm}$. As shown in Figure 1, after delivery via the inlet hole A, the dispersed phase flowed into 6 dead-end channels (yellow region). The four central dead-end channels has two MC arrays, fabricated along both sides of each dead-end channel, while the two peripheral dead-end channels possess only one $\mathrm{MC}$ array, resulting in a total of $10 \mathrm{MC}$ arrays. Each MC array was $9.54 \mathrm{~mm}$ long and consisted 
of 54 parallel MCs with a depth of $5 \mu \mathrm{m}$ and a width of $18 \mu \mathrm{m}$ (design 1) or 185 MCs with a depth of $4 \mu \mathrm{m}$ and a width of $8 \mu \mathrm{m}$ (design 2). Therefore, the total number of MCs in the chip was 540 or 1850 (Table 1). Each MC was $140 \mu \mathrm{m}$ long and connected to a shallow terrace at both ends. The terrace at the downstream end of the MCs was $60 \mu \mathrm{m}$ long (design 1) or $28 \mu \mathrm{m}$ long (design 2) and allowed for the dispersed phase to be confined after exiting the MCs, resulting in surface energy gradients needed for droplet detachment. The continuous phase was delivered through five inlet holes $\mathbf{B}$, placed at the upstream end of each cross-flow channel between the two terraces (green region of Figure 1). The droplets were removed through the outlet hole $\mathbf{C}$ located downstream of the cross-flow channels.

\section{Figure 2}

Anisotropic etching produces channels with sidewalls that form a $54.7^{\circ}$ angle with the substrate surface, as shown in Figure 2. This is due to etching the silicon atoms on the $\{100\}$ crystal plane at a faster rate than those on the $\{111\}$ plane. MCs with sharp edges are preferred in step emulsification compared to MCs with rounded corners produced by isotropic wet etching.

\subsection{Module Assembly/Droplet Generation}

The microchannel emulsification (MCE) module was made of stainless steel with a diameter of $100 \mathrm{~mm}$ and a height of $24 \mathrm{~mm}$. The top stainless steel plate had three orifices which served as slots for the connectors used to supply the dispersed and continuous phase into the device and to collect the generated emulsion. The orifices of the top plate were aligned such that one orifice delivered the dispersed phase to the inlet hole $\mathbf{A}$, while the other delivered the continuous phase to the five inlet holes $\mathbf{B}$. The third top plate orifice was connected to the collection hole $\mathbf{C}$ of the chip. 
A quartz glass provided for droplet observation from the bottom side via a metallurgical (reflective light) microscope. The module was filled with the continuous phase and the top plate was firmly fastened to form closed channels between the grooved silicon plate and glass plate. The dispersed and continuous phase were delivered using Harvard Apparatus 11 Elite syringe pumps from gastight glass syringes via separate syringe filters and medical tubing to the connectors attached to the top plate of the module. A hydrophobic $0.45 \mu \mathrm{m}$ polytetrafluoroethylene (PTFE) syringe filter was used for the dispersed phase, while a hydrophilic $0.2 \mu \mathrm{m}$ polysulfone (PS) filter was used for the continuous phase. The flow rate of the dispersed phase and continuous phase was set to $Q_{d}=$ $0.005 \mathrm{~mL} / \mathrm{h}$ and $Q_{c}=0.5 \mathrm{~mL} / \mathrm{h}$ for chip 2 and $Q_{d}=0.05 \mathrm{~mL} / \mathrm{h}$ and $Q_{c}=1 \mathrm{~mL} / \mathrm{h}$ for chip 1 . Droplet generation was observed and recorded using a color CCD camera (LCL-211H, Watec America Corp. USA) and Ulead Video Studio 11 SE DVD software (InterVideo Digital Technology Corporation).

\subsection{Droplet Generation Analysis}

The analysis of the acquired video images was carried out using ImageJ software. The mean diameter of the droplets generated at the i-th terrace was calculated using:

$$
\bar{d}_{i}=\sum_{1}^{n_{j}} d_{j} / n_{j}
$$

where $n_{j}$ is the number of droplets observed and $d_{j}$ is the diameter of a droplet. The coefficient of variation of droplet diameters at the $\mathrm{i}$-th terrace was calculated as:

$$
C V_{i}(\%)=\left(\sigma_{i} / \bar{d}_{i}\right) \times 100
$$

where $\sigma_{i}$ is the standard deviation of the droplet diameters generated at the $\mathrm{i}$-th terrace. The frequency of drop generation from a single channel was calculated using: 


$$
f_{M C}=\left(n_{f} y\right) / z
$$

where $z$ is the number of frames taken to generate $n_{f}$ droplets, and $y$ is the camera's frame rate. The mean frequency of drop generation at the $\mathrm{i}$-th terrace, $\bar{f}_{i}$, was calculated as an arithmetic mean of $f_{M C}$ values for all active channels on the terrace. The percent of active channels in the chip can be estimated using:

$$
k=N_{M C}^{a} / N_{M C} \times 100 \%=6 Q_{d} /\left(\pi N_{M C} \sum_{i=1}^{10} \bar{f}_{i} \bar{d}_{i}^{3}\right) \times 100 \%
$$

where $\mathrm{Q}_{\mathrm{d}}$ is the flowrate of dispersed phase, $N_{M C}$ is the total number of channels in the chip, and $N_{M C}^{a}$ is the number of active channels. The mean droplet diameter across the whole device can be calculated based on the mean droplet diameter and the mean frequency of drop generation at individual terraces using:

$$
d_{a v}=\left(\sum_{i=1}^{10} \bar{d}_{i} \bar{f}_{i}\right) / \sum_{i=1}^{10} \bar{f}_{i}
$$

\subsection{Microparticle Production and Characterisation}

Particle production. Emulsions were collected in the collection syringe and the droplets were solidified upon DCM evaporation for $24 \mathrm{~h}$ under room temperature.

Confocal Laser Scanning Microscopy (CLSM) and sizing. CLSM images were acquired using a Nikon Eclipse TE300 confocal inverted microscope connected to a computer running Zeiss LaserSharp 2000 software. A suspension of microparticles from evaporated droplets was placed on a microscopic slide and excited with argon laser at a wavelength of $488 \mathrm{~nm}$ and helium-neon laser with a wavelength of $543 \mathrm{~nm}$. The total emission was separated into two images captured by two photomultiplier tubes (PMTs): PMT1 captured fluorescence at 515 $\pm 30 \mathrm{~nm}$ (green region) and 
PMT2 captured fluorescence above $570 \mathrm{~nm}$ (yellow-red region). Acquired images were analysed with Image J software for particle sizing. The CV of particle diameters was estimated using Eq. (2). For the total polymer concentration in the dispersed phase of $3 \mathrm{wt} \%$, the predicted particle diameter based on zero porosity of the polymer matrix is given by:

$$
d_{p}=d_{a v} \sqrt[3]{(0.03) \rho_{d} / \rho_{p}}
$$

where $\rho_{d}$ and $\rho_{p}$ are the density of the dispersed phase and formed particles.

\section{Results and Discussion}

\subsection{Droplet Generation Behaviour}

Video 1 and Figure $\mathrm{S} 1$ in the supplementary material shows generation of droplets in chip 1 and droplet streams generated from different terraces heading towards the outlet hole C. The dispersed phase expands on the terrace into a disc-like shape. If the contact angle at the solid-oil-water interface on the terrace is very low, the Laplace pressure of the dispersed phase on the terrace is $p_{1}=\gamma\left(1 / r_{1}+2 / H_{T}\right)$, where $\gamma$ is the interfacial tension, $H_{T}$ is the height of the terrace and $r_{1}$ is the radius of the dispersed phase disc on the terrace. The disc expands radially as more fluid flows through the channel, but $p_{1}$ does not change because $H_{T} / 2 \ll r_{1}$ and $p_{1} \approx 2 \gamma / H_{T}$. When the dispersed phase reaches the edge of the terrace and enters the well, it is no longer confined and expands in three dimensions, assuming a bulbous shape. The Laplace pressure in the bulb is $p_{2}=$ $2 \gamma / r_{2}$, where $r_{2}$ is the radius of the bulb. Because $r_{2} » H_{T} / 2$ (Figure S2a), then $p_{1} » p_{2}$. The difference in Laplace pressure of the dispersed phase on the terrace and in the well $\left(p_{1}-p_{2}\right)$ induces a sudden flow into the well, which rapidly depletes the dispersed phase from the terrace and forms a neck that eventually breaks up via a Rayleigh-Plateau instability [23, 32]. 
The micrographs of droplet generation from two different chips are shown in Figure 3. The shape of the interface on the terrace was mostly symmetric with respect to the channel axis, indicating negligible interactions between the plate surface and the dispersed phase. The silicon plate was oxidized in a plasma reactor prior to each experiment to allow the growth of a hydrophilic film of silicon dioxide on the silicon surface and minimise its wetting with the organic phase.

\section{Figure 3}

Satellite droplets that can be seen on the terrace in Figure 3(d) were formed as a result of multiple neck ruptures during droplet formation. Satellite droplets are common for breakups governed by capillary instabilities [33] and have often been observed in T junctions, flow focusing nozzles, and numerical simulations [34]. In Figure 3(a)-(c), the continuous phase flow was temporarily shut down to allow droplets to self-assemble into regular hexagonal arrays to illustrate their high size uniformity. The droplets in closely packed arrays were stable against coalescence due to protective layer of PVA adsorbed at the interface. Partially hydrolysed PVA is a copolymer of poly(vinyl acetate) and poly(vinyl alcohol). Hydrophobic vinyl acetate groups were in contact with the organic phase and hydrophilic vinyl alcohol groups are exposed to the aqueous phase. At low PVA concentrations, droplets are susceptible to bridging flocculation as a result of the adsorption of PVA chains onto the surface of two or more droplets simultaneously. At higher PVA concentrations, when the droplet surface is covered by PVA to more than $50 \%$ of the saturation coverage, steric stabilization dominates over bridging flocculation and the droplets are stable against aggregation [35].

\subsection{Consistency of Droplet Generation in Chip 1}




\section{Table 2}

Average droplet size. The average droplet size, $d_{a v}$, across the whole device over $7 \mathrm{~h}$ was 25.8 $\mu \mathrm{m}$ (Figure 4a). The dimensionless droplet diameter, $d_{a v} / H_{T}$, i.e. the average droplet diameter divided by the terrace height, depends on the ratio of the viscosities of the dispersed and continuous phase, $\xi=\eta_{d} / \eta_{c}$. If $\xi$ is above a certain critical value, $\xi_{c r}$, the droplet size is not affected by $\xi$ and $d_{a v} / H_{T}$ is 3.8-4.2 for typical terrace lengths [36]. At $\xi<\xi_{c r}$, the droplet size was found to increase with decreasing $\xi$, but below a certain minimum value of $\xi$, uniform droplets cannot be produced [36]. $\xi_{\min }$ typically ranged between 0.16 and 0.48 and $d_{a v} / H_{T}$ at $\xi=\xi_{\min }$ was 5-5.2 [36]. In this study, the viscosity ratio was $\xi=0.21$ and $d_{a v} / H_{T}$ was 5.2 , which was close to the $d_{a v} / H_{T}$ values reported at $\xi=\xi_{\min }[36]$.

Coefficient of variation of droplet sizes. The $C V_{a v}$ value for the entire droplet population generated over $7 \mathrm{~h}$ was $2.8 \%$, indicating that the droplet size distribution was monodisperse (CV $<3 \%$ ). Other microfluidic devices, such as $\mathrm{T}$-junctions, flow focusing generators, and glass capillary devices are also capable of generating droplets with $C V_{a v}<3 \%$ [33].

\section{Figure 4}

Droplet size and $\mathbf{C V}$ for individual terraces. The average droplet diameter, $\bar{d}_{i}$ and the coefficient of variation, $\overline{C V}_{i}$ on different terraces $(i=1-10)$ as a function of time are shown in Figure 4 and Table 2 . The terrace-average $\bar{d}_{i}$ value, i.e. the arithmetic mean of $\bar{d}_{i}$ values for all terraces at a certain time, changed slightly over time from $25.6 \mu \mathrm{m}$ after $2 \mathrm{~h}$ to $26.0 \mu \mathrm{m}$ after $4 \mathrm{~h}$, and to $25.9 \mu \mathrm{m}$ after $6 \mathrm{~h}$ (Table 2). The terrace-to-terrace variations in $\bar{d}_{i}$ were also very small, with the minimum time-average $\bar{d}_{i}$ value of $25.5 \mu \mathrm{m}$ observed in terrace 1 and the maximum value of $26.1 \mu \mathrm{m}$ in terrace 7 (Table 2). Slightly smaller $\bar{d}_{i}$ values were observed in peripheral terraces 
(1-3 and 9-10) as compared to central terraces (4-8), which was due to higher droplet generation frequencies $\bar{f}_{i}$ at central terraces.

The time-average $C V_{i}$ value over $7 \mathrm{~h}$ for the droplets generated from a single terrace varied from $1.2 \%$ for terrace 10 to $2.1 \%$ for terrace 6 . Therefore, droplets generated from any single terrace were more uniform in size than the total population of droplets collected from all terraces. The terrace-average $C V_{i}$ value showed small random variations with time between $1.4 \%$ and $1.9 \%$.

\section{Figure 5}

Drop generation frequencies for individual channels. The $f_{M C}$ values for all MCs in Chip 1 measured after 2, 4, and $6 \mathrm{~h}$ of operation are shown in the supplementary material (Tables S1-S3). The drop generation frequency from any single channel varied randomly between 0 and $10 \mathrm{~Hz}$ (Tables S1-S3). The average fluid velocity in a channel is given by: $\bar{U}_{M C}=\left(\pi d_{a v}^{3} / 6\right)\left(f_{M C} / A\right)$, where $A$ is the cross-sectional area of the channel. From this equation, $\bar{U}_{M C} \leq 0.56 \mathrm{~mm} / \mathrm{s}$ for $f_{M C} \leq 10 \mathrm{~Hz}, d_{a v}=25.8 \mu \mathrm{m}$, and $A=160 \mu \mathrm{m}^{2}$. This $\bar{U}_{M C}$ value is lower than the critical velocity for the dripping-jetting transition (1.6-2.3 mm), found by Sugiura et al. [39] for SDS-stabilised triolein droplets. Therefore, droplets were formed in dripping regime in all MCs. The $f_{M C}$ values at the channels located close to each other were similar (Table S1-S3), which shows that local hydrodynamic conditions in a chip change gradually along the channels. The same behavior was observed in membrane emulsification using microsieve membranes with almost identical droplet generation frequencies at some pores located close together [38]. Inactive channels tend to group together, indicating that droplet formation dynamics was strongly coupled. For example, in Table S1, 7 out of 11 inactive channels in terrace 3 were were located within neighbouring channels. 
Percentage of active channels. The zero value of $f_{M C}$ in Tables S1, S2, and S3 means that the corresponding channel was inactive, i.e. did not produce any droplet at the time of observation. Inactive pores were also found during formation of droplets at the surface of a silicon nitride microsieve [37] and SPG membrane [38]. All pores of an isoporous microsieve membrane should become active at the same pressure because they all have the same size. However, only $16 \%$ of the pores were active at the pressure which was 3 times higher than the capillary pressure [38]. It was explained by the local decrease in pressure occurring as soon as the dispersed phase starts to flow through some of the pores, preventing other pores to become active.

After $2 \mathrm{~h}$ of operation, $89 \%$ of the channels were active with the terrace-to-terrace variations in the percentage of active channels ranging from $76 \%$ to $100 \%$ (Table 2). After $4 \mathrm{~h}, 91 \%$ of all channels were active with at least $81 \%$ of active channels on each terrace. After $6 \mathrm{~h}$, the percentage of active channels reached $95 \%$ with at least $91 \%$ of active channels observed on each terrace. The number of active channels increased with time probably due to decrease in capillary pressure in the channels. According to the Young-Laplace equation, the capillary pressure in a rectangular microchannel is given by:

$$
p_{c}=\gamma\left(\frac{\cos \theta_{b}+\cos \theta_{t}}{D_{M C}}+\frac{\cos \theta_{l}+\cos \theta_{r}}{W_{M C}}\right)
$$

where $\gamma$ is the interfacial tension, $D_{M C}$ and $W_{M C}$ are the depth and width of a microchannel, and $\theta_{b}, \theta_{t}, \theta_{l}$, and $\theta_{r}$ are the contact angles at the bottom, top, left, and right side of the channel, respectively. The contact angles on all four sides of the channel increased over time due to wetting of the channel walls with the dispersed phase and hence, $p_{c}$ decreased with time. It should be noted that the channel walls are composed of cover glass on the top side and grooved silicon plate on the 
remaining sides. A decrease in $p_{c}$ made it easier for the dispersed phase to penetrate the channels and thus the number of active channels increased.

Mean drop generation frequencies for individual terraces. The $\bar{f}_{i}$ values for all terraces as a function of time are shown in Figure 5. The $\bar{f}_{i}$ values varied between 2.0 and $3.3 \mathrm{~Hz}$ depending on the terrace position and time. Generally, the smallest $\bar{f}_{i}$ values were observed in peripheral terraces, probably due to the higher percentage of active channels in these terraces compared to central ones. Since the dispersed phase flow rate was constant with time, the smallest $\bar{f}_{i}$ values were observed after $6 \mathrm{~h}$, due to the highest percentage of active channels.

\subsection{Consistency of Droplet Generation in Chip 2}

Figure 6

Droplet size and CV. Figure 6 shows the average droplet diameter, $\bar{d}_{i}$ and the coefficient of variation, $C V_{i}$ on each terrace of chip 2 as a function of time. The minimum $\bar{d}_{i}$ value of $13.2 \mu \mathrm{m}$ was observed in terrace 1 at $0.5 \mathrm{~h}$, while the maximum $\bar{d}_{i}$ value of $16.3 \mu \mathrm{m}$ was observed in terrace 6 at $1.5 \mathrm{~h}$. The average droplet diameter $\left(d_{a v}\right)$ across the whole device over $2.5 \mathrm{~h}$ was $14.2 \mu \mathrm{m}$ with negligible fluctuations with time between $14.0 \mu \mathrm{m}$ and $14.5 \mu \mathrm{m}$ (Table S4 in the supplementary material). The $d_{a v}$ value in chip 2 was 1.8 times smaller than that in chip 1 , due to 2.1 times smaller equivalent diameter of the MCs in chip 2 (Table 1).

The $C V_{i}$ values were higher than in chip 1 and ranged from $2.3 \%$ in terrace 2 at $0.5 \mathrm{~h}$ to $5 \%$ in terrace 3 at $2.5 \mathrm{~h}$. The average $C V_{i}$ values across all terraces were higher than the $C V_{i}$ values for individual terraces and varied with time between $3.8 \%$ and 5.9\% (Table S4). The observed trend 
that the droplet size uniformity deteriorates with decreasing the MC size was found in previous studies. Using straight-through MC plates, Kobayashi et al. [40] found an increase in CV from $2.7 \%$ to $5.5 \%$ when the droplet size decreased from $9.8 \mu \mathrm{m}$ to $4.4 \mu \mathrm{m}$ droplets.

\section{Figure 7}

Drop generation frequencies. The mean drop generation frequencies on individual terraces as a function of time are shown in Figure 7. The average drop generation frequency across the whole device was very stable and varied with time in a narrow range of 1.3-1.7 Hz (Table S4), but the droplet production rates at individual terraces fluctuated between $0.6 \mathrm{~Hz}$ and $2.8 \mathrm{~Hz}$ (Figure 7). The percentage of active channels in chip 2 was only $27-38 \%$ (Table S4). The hydrodynamic resistance of the channels increases on decreasing the size of the channels. At constant flow rate, the higher resistance should lead to higher pressure drop along the channels in chip 2, which should help to activate more channels. However, the dispersed phase flow rate in chip 2 was 10 times smaller than the flow rate in chip 1. Within dripping regime, the smaller the dispersed phase flow rate, the smaller the number of active channels and the smaller the droplet production frequency [41]. Kobayashi et al. [40] found that less than $1 \%$ of the MCs were active in straight-through plates when droplets with an average diameter of $4.4 \mu \mathrm{m}$ were produced.

\subsection{Generation of Polymeric Particles}

Composite polymer particles were formed upon solvent evaporation from the generated droplets. Figure 7 shows the droplet and particle size distribution for the two chips used. The average droplet and particle diameters were $25.5 \mu \mathrm{m}$ and $8.8 \mu \mathrm{m}$ respectively for chip 1 and $14.1 \mu \mathrm{m}$ and $4.9 \mu \mathrm{m}$ respectively for chip 2 . The average particle size for chip 2 was smaller than $5 \mu \mathrm{m}$, which means 
that the produced particles are smaller than the smallest blood vessels and can be used in intravenous drug delivery.

\section{Figure 8}

From Eq. (6), the predicted particle diameters based on complete solvent evaporation and zero particle porosity are $8.3 \mu \mathrm{m}$ for chip 1 and $4.8 \mu \mathrm{m}$ for chip 2 , which are only slightly smaller values than the experimental values. The deviations between the predicted and produced particle diameters occurred due to formation of pores in the polymer matrix, as reported elsewhere [42].

\section{Figure 9}

The CLSM images of the generated particles are shown in Figure 9. The particles have a homogeneous surface morphology, probably because the rate of solvent evaporation was faster that the rate of polymer diffusion in the dispersed phase. The fluorescent dyes added to the organic phase exhibit different affinities to different polymers, i.e. Rh6G preferentially adsorbs to PLA, while Nile Red shows higher affinity to PCL [43]. Therefore, a partial or complete polymer separation and the formation of patchy or Janus particles would be visible on CLSM images due to accumulation of Rh6G in PLA patches and entrapment of Nile Red in PCL. The generated composite particles have a tuneable size and narrow size distribution and can be used in pharmaceutical applications as biodegradable microcarriers. The PLA to PCL ratio can be adjusted to achieve optimum biodegradation rate and high compatibility with the entrapped drug.

\subsection{Mitigation Measures to Prolong Droplet Generation Time and Increase Droplet Throughput}


Several measures can be taken to maximise the throughput per channel and the percentage of active channels in a chip. Before each experiment, the silicon chip and cover glass must be treated with oxygen plasma or UV light/ozone to improve hydrophilic properties of all surfaces in contact with the dispersed phase and minimise their wetting with the dispersed phase. Drop generation in step emulsification is driven by the difference in Laplace pressure of the dispersed phase on the terrace and in the well. For non-wetted terrace walls, the difference in Laplace pressure is given by: $p_{1}-$ $p_{2}=2 \gamma\left(1 / H_{T}-1 / r_{2}\right)$. The Laplace pressure of the dispersed phase on the terrace depends on the radius of curvature of the oil-aqueous interface on the terrace. If the terrace walls are sufficiently hydrophilic, the contact angle at the oil-water-solid interface will be low (Figure S2b in the supplement) and the Laplace pressure on the terrace will be high enough to drive the dispersed phase into the well, which will lead to stable drop generation. The contact angle may increase after prolonged contact of the terrace walls with the organic phase (Figure S2c). If it happens, the Laplace pressure difference may become too low to drive the dispersed phase out of the terrace and large non-uniform droplets will be formed. If the terrace walls are wetted with the organic phase, the Laplace pressure difference will be reduced to: $p_{1, w e t}-p_{2}=2 \gamma\left(1 / x-1 / r_{2}\right)$, where $x / 2$ is the radius of curvature of the interface for wetted walls $\left(x>H_{T}\right.$ and $\left.p_{1, \text { wet }}<p_{1}\right)$.

The contact angle at air-water-silicon interface for a clean UV/ozone-treated silicon surface was $16.9^{\circ}$, as measured by a Krüss Model DSA 100 Advanced Drop Shape Analyzer. After 10 min of ultrasound treatment with DCM, the contact angle increased to $32.4^{\circ}$ due to silicon exposure to the hydrophobic solvent. After evaporating the dispersed phase from the chip surface, the contact angle further increased to $59.4^{\circ}$, due to deposition of PLA and PCL onto silicon surface. The polymers can be deposited onto the channel walls during drop generation if the forming drop 
resides on the terrace for a prolonged period of time during which the solvent can completely diffuse out of the droplet into the aqueous stream leaving behind a solid polymer. Therefore, all silicon and glass surfaces must be oxidised to minimize sticking of the forming drops to the walls.

The percentage of active channels can be increased by loading the module with a $5 \mathrm{wt} \%$ PVA solution before delivery of the dispersed phase, but after starting drop generation, a $1.5 \mathrm{wt} \%$ PVA solution can be used as the continuous phase. The exact mechanism of channel activation with a high initial PVA content is still unknown, but probably micelles present in the PVA solution at high concentration can help to overcome the capillary pressure in the channel and transport the organic phase through the channel.

\section{Conclusions}

Microchannel (step) emulsification using cross flow microfluidic chips consisted of up to 1,850 microchannels fabricated on 10 parallel terraces was applied to stably produce monodispersed $\mathrm{O} / \mathrm{W}$ emulsions with a low viscosity ratio of the dispersed to continuous phase of $\xi=0.21$. The droplet size was 2.7-3.1 greater than the hydraulic diameter of the channels and the coefficient of variation was less than 5\% in both chips. The droplet generation frequencies and fluid velocities at individual channels varied considerably, but it had no significant impact on the droplet size, which confirms the robustness of step emulsification. The droplet production rates for the channels located close together were similar, indicating that the droplet formation dynamics was coupled. In chip 1, the average droplet size showed negligible variations over $7 \mathrm{~h}$ and the percentage of active channels increased with time. After $6 \mathrm{~h}$ of continuous production, 95\% of all channels 
produced droplets, the percentage of active channels on each terrace was $91 \%$ or more, and the coefficient of variation of droplet sizes at individual terraces was only 1.2-2.1\%.

The results clearly indicate that microchannel (step) emulsification technology in combination with solvent evaporation is very suitable for long-term production of synthetic biodegradable polymer particles. The particle size can be precisely adjusted by the microchannels and terraces and the droplet throughput can be controlled by the total number of microchannels.

\section{Acknowledgements}

The authors gratefully acknowledge the financial support from the JSPS-UK BRIDGE Fellowship (BR 130302) awarded to Dr Vladisavljević.

\section{References}

[1] S. Xu, Z. Nie, M. Seo, P. Lewis, E. Kumacheva, H.A. Stone, P. Garstecki, D.B. Weibel, I. Gitlin, G.M. Whitesides, Generation of monodisperse particles by using microfluidics: control over size, shape, and composition, Angew. Chem., Int. Ed. 44 (2005) 724-728. doi: 10.1002/anie. 200462226

[2] G.T. Vladisavljević, I. Kobayashi, M. Nakajima, Production of uniform droplets using membrane, microchannel and microfluidic emulsification devices, Microfluid. Nanofluid. 13 (2012) 151-178. doi:10.1007/s10404-012-0948-0

[3] G.T. Vladisavljević, N. Khalid, M.A. Neves, T. Kuroiwa, M. Nakajima, K. Uemura, S. 
Ichikawa, I. Kobayashi, Industrial lab on a chip: design, applications and scale up for drug discovery and delivery, Adv. Drug Del. Rev. 65 (2013) 1626-1663. doi:

10.1016/j.addr.2013.07.017

[4] A. Jillavenkatesa, S.J. Dapkunas, L.H. Lum, Particle Size Characterization, National Institute of Standards and Technology, Special Publication 960-1, 2001, p. 149.

[5] J.H. Kim, T.Y. Jeon, T.M. Choi, T.S. Shim, S.H. Kim, S.M. Yang, Droplet microfluidics for producing functional microparticles, Langmuir 30 (2014) 1473-1488. doi: $10.1021 / \mathrm{la} 403220 \mathrm{p}$

[6] Y. Zhua, Q. Fang, Analytical detection techniques for droplet microfluidics - A review, Anal. Chim. Acta 787 (2013) 24-35. doi: 10.1016/j.aca.2013.04.064

[7] N. Shembekar, C. Chaipan, R. Utharala, C.A. Merten, Droplet-based microfluidics in drug discovery, transcriptomics and high-throughput molecular genetics, Lab Chip 16 (2016) 1314-1331. doi: 10.1039/C6LC00249H

[8] L. Mazutis, J. Gilbert, W.L. Ung, D.A. Weitz, A.D. Griffiths, J.A. Heyman, Single-cell analysis and sorting using droplet-based microfluidics, Nature Protocols 8 (2013) 870-891. doi: $10.1038 /$ nprot. 2013.046

[9] R. Seemann, M. Brinkmann, T. Pfohl, S. Herminghaus, Droplet based microfluidics, Rep. Prog. Phys. 75 (2012) 016601. doi: 10.1088/0034-4885/75/1/016601

[10] A. Ofner, D.G. Moore, P.A. Rühs, P. Schwendimann, M. Eggersdorfer, E. Amstad, D.A. Weitz, A.R. Studart, High-throughput step emulsification for the production of functional materials using a glass microfluidic device, Macromol. Chem. Phys. 218 (2017) 1600472. doi: $10.1002 /$ macp. 201600472

[11] E. Amstad, M. Chemama, M. Eggersdorfer, L.R. Arriaga, M. P. Brenner, D.A. Weitz, 
Robust scalable high throughput production of monodisperse drops, Lab Chip 16 (2016) 4163-4172. doi: 10.1039/c6lc01075j

[12] M.K. Mulligan, J.P. Rothstein, Scale-up and control of droplet production in coupled microfluidic flow-focusing geometries, Microfluid. Nanofluid. 13 (2012) 65-73. doi: $10.1007 / \mathrm{s} 10404-012-0941-7$

[13] M.B. Romanowsky, A.R. Abate, A. Rotem, C. Holtze, D.A. Weitz, High throughput production of single core double emulsions in a parallelized microfluidic device, Lab Chip 12 (2012) 802-807. doi: 10.1039/C2LC21033A

[14] T. Nisisako, T. Ando, T. Hatsuzawa, High-volume production of single and compound emulsions in a microfluidic parallelization arrangement coupled with coaxial annular world-to-chip interfaces, Lab Chip 12 (2012) 3426-3435. doi: 10.1039/c2lc40245a

[15] T. Femmer, A. Jans, R. Eswein, N. Anwar, M. Moeller, M. Wessling, A.J.C. Kuehne, High-throughput generation of emulsions and microgels in parallelized microfluidic dropmakers prepared by rapid prototyping, ACS Appl. Mater. Interfaces 7 (2015) 12635-12638. doi: 10.1021/acsami.5b03969

[16] H.H. Jeong, V.R. Yelleswarapu, S. Yadavali, D. Issadore, D. Lee, Kilo-scale droplet generation in three-dimensional monolithic elastomer device (3D MED), Lab Chip 15 (2015) 4387-4392. doi: 10.1039/c5lc01025j

[17] T. Kawakatsu, Y. Kikuchi, M. Nakajima, Regular-sized cell creation in microchannel emulsification by visual microprocessing method, J. Am. Oil Chem. Soc. 74 (1997) 317321. doi: $10.1007 / \mathrm{s} 11746-997-0143-8$

[18] M. L. Eggersdorfer, W. Zheng, S. Nawar, C. Mercandetti, A. Ofner, I. Leibacher, S. Koehler, D.A. Weitz, Tandem emulsification for high-throughput production of double 
emulsions, Lab Chip 17 (2017) 936-942. doi: 10.1039/c6lc01553k

[19] R. Dangla, E. Fradet, Y. Lopez, C.N. Baroud, The physical mechanisms of step emulsification, J. Phys. D: Appl. Phys. 46 (2013) 114003. doi:

http://dx.doi.org/10.1088/0022-3727/46/11/114003

[20] F. Dutka, A.S. Opalski, P. Garstecki, Nano-liter droplet libraries from a pipette: step emulsificator that stabilizes droplet volume against variation in flow rate, Lab Chip 16 (2016) 2044-2049. doi: 10.1039/c6lc00265j

[21] N. Mittal, C. Cohenb, J. Bibette, N. Bremond, Dynamics of step-emulsification: From a single to a collection of emulsion droplet generators, Phys. Fluids 26 (2014) 082109 (2014). doi: http://dx.doi.org/10.1063/1.4892949

[22] W. Postek, T.S. Kaminski, P. Garstecki, A passive microfluidic system based on step emulsification allows the generation of libraries of nanoliter-sized droplets from microliter droplets of varying and known concentrations of a sample, Lab Chip 17 (2017) 1323-1331. doi: 10.1039/C7LC00014F

[23] S. Sugiura, M. Nakajima, N. Kumazawa, S. Iwamoto, M. Seki, Characterization of spontaneous transformation-based droplet formation during microchannel emulsification, J. Phys. Chem. B. 106 (2002) 9405-9409. doi: 10.1021/jp0259871

[24] R. Dangla, S.C. Kayi, C.N. Baroud, Droplet microfluidics driven by gradients of confinement, Proc. Natl. Acad. Sci. U. S. A. 110 (2013) 853-858. doi: 10.1073/pnas. 1209186110

[25] G. Vladisavljević, I. Kobayashi, M. Nakajima, Effect of dispersed phase viscosity on maximum droplet generation frequency in microchannel emulsification using asymmetric straight-through channels, Microfluid. Nanofluid. 10 (2011) 1199-1209. 
doi:10.1007/s10404-010-0750-9

[26] I. Kobayashi, K. Uemura and M. Nakajima, Formulation of monodisperse emulsions using submicron-channel arrays, Colloids Surf. A 296 (2007) 285-289. doi:10.1016/j.colsurfa.2006.09.015

[27] I. Kobayashi, T. Takano, R. Maeda, Y. Wada, K. Uemura and M. Nakajima, Straightthrough microchannel devices for generating monodisperse emulsion droplets several microns in size, Microfluid. Nanofluid. 4 (2008) 167-177. doi: 10.1007/s10404-007-01672

[28] I. Kobayashi, M.A. Neves, Y. Wada, K. Uemura, M. Nakajima, Large microchannel emulsification device for mass producing uniformly sized droplets on a liter per hour scale, Green Process. Synth. 1 (2012) 353-362. doi: https://doi.org/10.1515/gps-2012-0023

[29] T. Kawakatsu, H. Komori, M. Nakajima, Y. Kikuchi, T. Yonemoto, Production of monodispersed oil-in-water emulsion using crossflow-type silicon microchannel plate, J. Chem. Eng. J. 32 (1999) 241-244. doi: 10.1252/jcej.32.241

[30] I. Kobayashi, Y. Wada, K. Uemura, M. Nakajima, Microchannel emulsification for mass production of uniform fine droplets: integration of microchannel arrays on a chip, Microfluid. Nanofluid. 8 (2010) 255-262. doi: 10.1007/s10404-009-0501-y

[31] Y. Zhang, I. Kobayashi, M.A. Neves, K. Uemura, M. Nakajima, Long-term continuous production of soybean oil-in-water emulsions by microchannel emulsification, Food Sci. Technol. Res. 19 (2013) 995-1001. doi: http://doi.org/10.3136/fstr.19.995

[32] X. Huang, M. Eggersdorfer, J. Wu, C.X. Zhao, Z. Xu, D. Chen, D.A. Weitz, Collective generation of milliemulsions by step-emulsification, RCS Adv. 7 (2017) 14932-14938. doi: 10.1039/C7RA00935F 
[33] P. Zhu, L. Wang, Passive and active droplet generation with microfluidics: a review, Lab Chip 17 (2017) 34-75. doi: 10.1039/C6LC01018K

[34] S.A. Nabavi, S. Gu, G.T. Vladisavljević, E.E. Ekanem, Dynamics of double emulsion break-up in three phase glass capillary microfluidic devices, J. Colloid Interface Sci. 450 (2015) 279-287. doi: http://dx.doi.org/10.1016/j.jcis.2015.03.032

[35] R. Othman, G.T. Vladisavljević, H. Shahmohamadi, Z.K. Nagy, R.G. Holdich, Formation of size-tuneable biodegradable polymeric nanoparticles by solvent displacement method using micro-engineered membranes fabricated by laser drilling and electroforming, Chem. Eng. J. 304 (2016) 703-713. doi: 10.1016/j.cej.2016.07.010

[36] K. van Dijke, I. Kobayashi, K. Schroën, K. Uemura, M. Nakajima, R. Boom, Effect of viscosities of dispersed and continuous phases in microchannel oil-in-water emulsification, Microfluid. Nanofluid. 9 (2010) 77-85. doi: 10.1007/s10404-009-0521-7

[37] A.J. Abrahamse, R. van Lierop, R.G.M. van der Sman, A. van der Padt, R.M. Boom, Analysis of droplet formation and interactions during cross-flow membrane emulsification, J. Membr. Sci. 204 (2002) 125 -137. doi: 10.1016/S0376-7388(02)00028-5

[38] G.T. Vladisavljević, I. Kobayashi, M. Nakajima, R.A. Williams, M. Shimizu, T. Nakashima, Shirasu Porous Glass membrane emulsification: Characterisation of microstructure by high resolution $\mathrm{x}$-ray microtomography and microscopic visualisation of droplet formation in real time, J. Membr. Sci. 302 (2007) 243-253. doi: 10.1016/j.memsci.2007.06.067

[39] S. Sugiura, M. Nakajima, M. Seki, Effect of channel structure on microchannel emulsification, Langmuir 18 (2002) 5708-5712. doi: 10.1021/la025813a

[40] I. Kobayashi, T. Takano, R. Maeda, Y. Wada, K. Uemura, M. Nakajima, Straight-through 
microchannel devices for generating monodisperse emulsion droplets several microns in size, Microfluid. Nanofluid. 4 (2008) 167-177. doi: 10.1007/s10404-007-0167-2

[41] S. Sugiura, M. Nakajima, J. Tong, H. Nabetani, M. Seki, Preparation of monodispersed solid lipid microspheres using a microchannel emulsification technique, J. Colloid Interface Sci. 227 (2000) 95-103. doi: https://doi.org/10.1006/jcis.2000.6843

[42] E.E. Ekanem, Z. Zhang, G.T. Vladisavljević, Facile microfluidic production of composite polymer core-shell microcapsules and crescent-shaped microparticles, J. Colloid Interface Sci. 498 (2017) 387-394. doi: https://doi.org/10.1016/j.jcis.2017.03.067

[43] E.E. Ekanem, S.A. Nabavi, G.T. Vladisavljević, S. Gu, Structured biodegradable polymeric microparticles for drug delivery produced using flow focusing glass microfluidic devices, ACS Appl. Mater. Interfaces 7 (2015) 23132-23143. doi: 10.1021/acsami.5b06943 


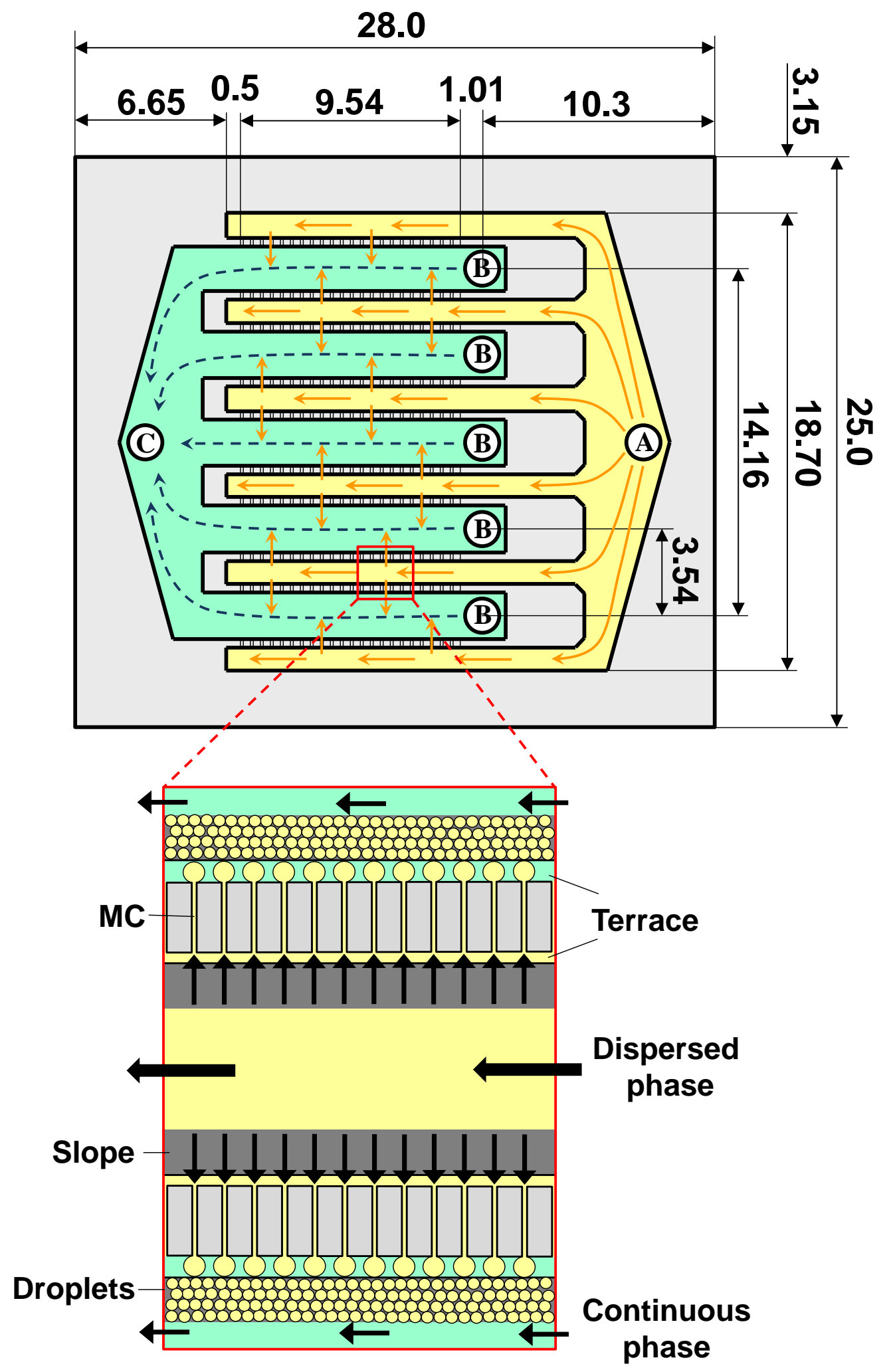

Figure 1: A schematic of CMS6 silicon plate (chip), showing the layout of the dead-end channels for the supply of dispersed phase (yellow), the cross-flow channels for continuous phase (turquoise), and the terraces with MCs. All dimensions shown in the figure are in $\mathrm{mm}$. 
(a) Chip design 1
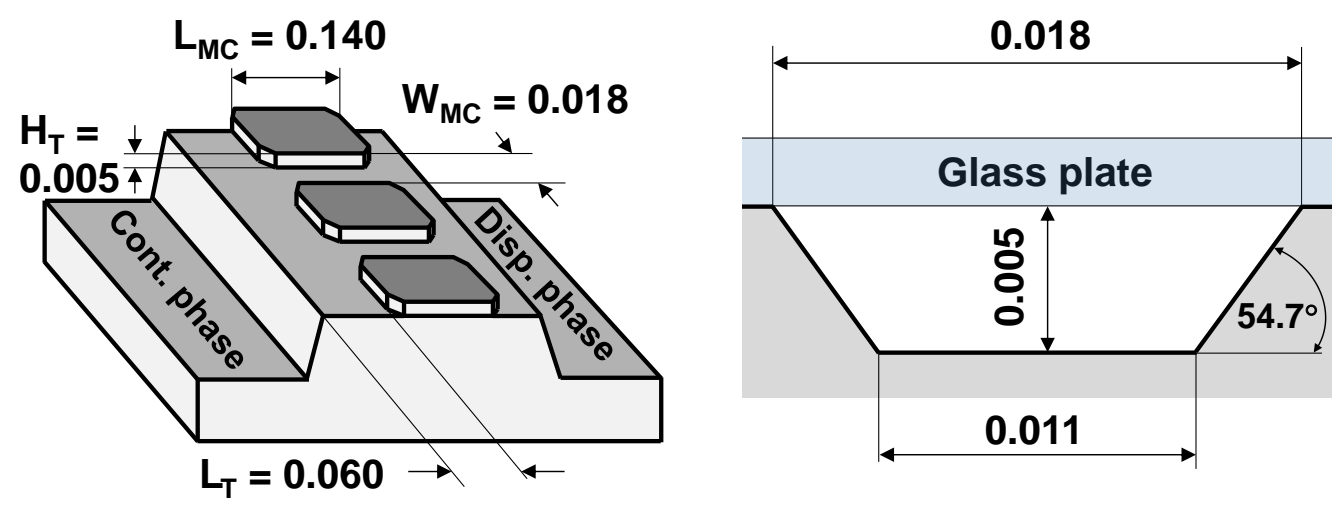

(b) Chip design 2
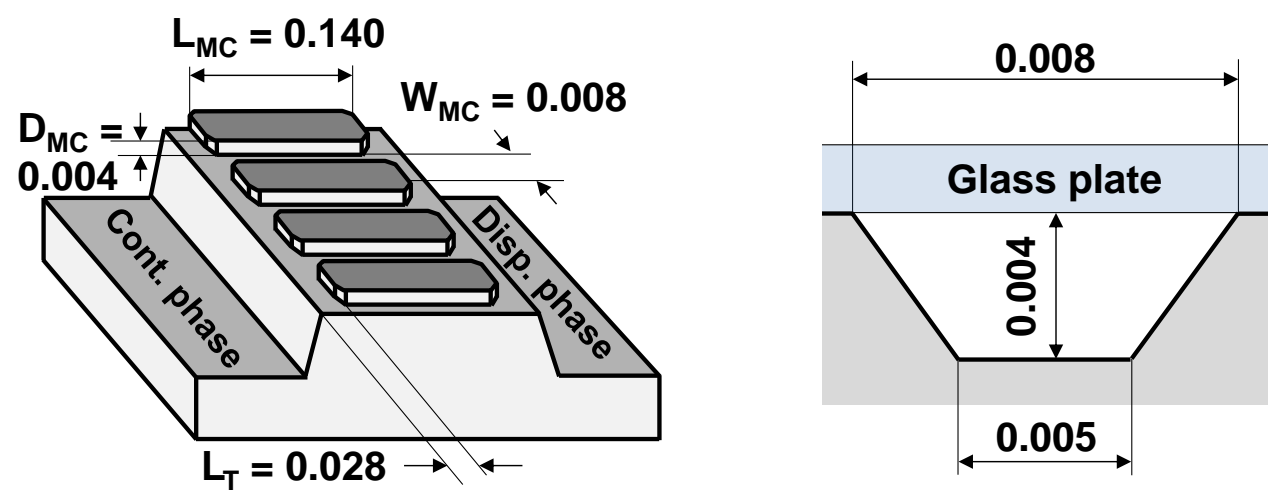

Figure 2: The dimensions of microchannels and terraces in both chips used in this work. An anisotropic wet etch on a silicon wafer creates microchannels with a trapezoidal cross section. All dimensions are in mm. 


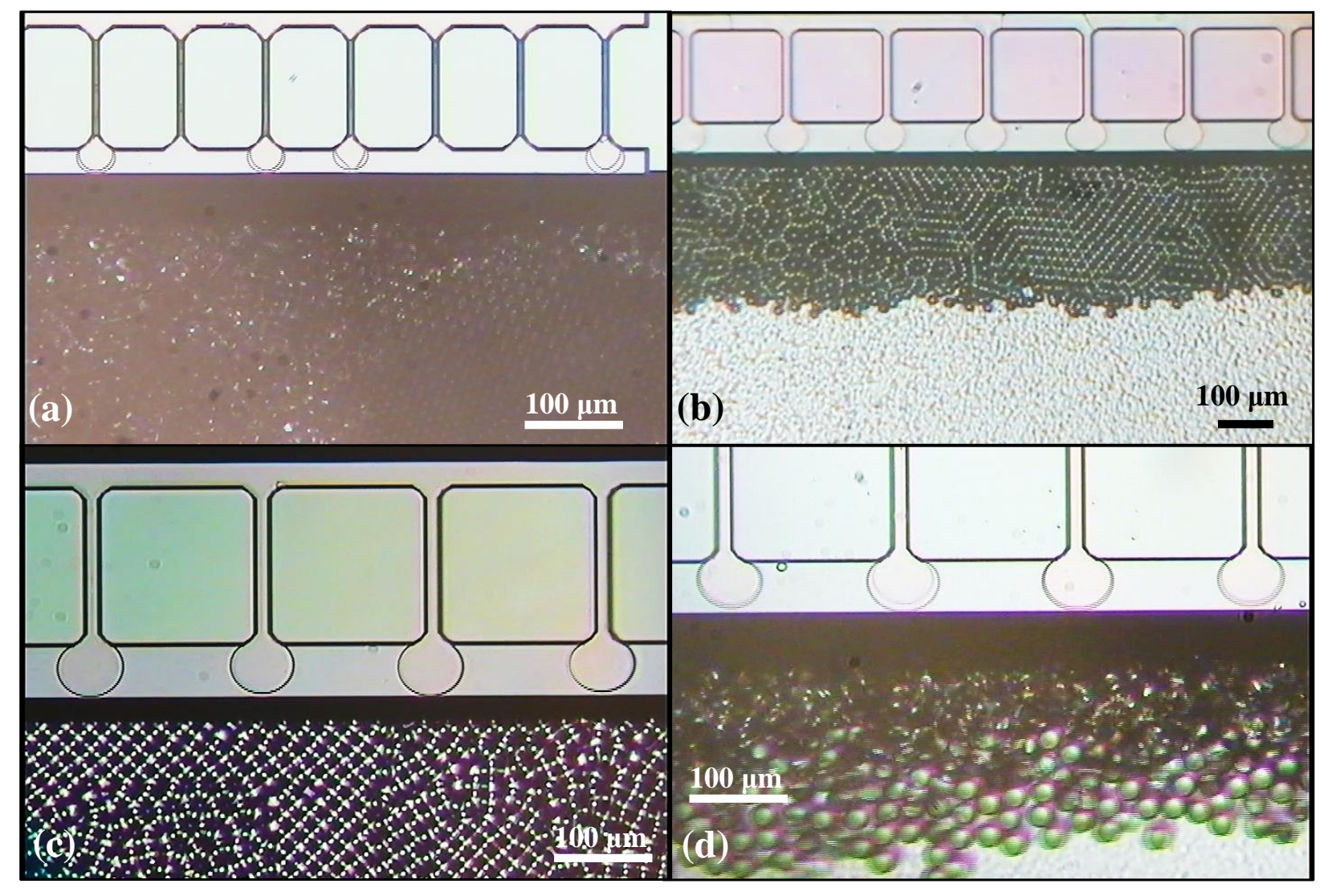

Figure 3: (a) Droplet generation in Chip 2 after $2.5 \mathrm{~h}$ of operation; (b-d) Droplet generation in Chip 1 after $7 \mathrm{~h}$ of operation. In (a)-(c), the continuous phase supply was temporarily shut down to allow self-assemble of generated droplets to into regular hexagonal arrays, illustrating their high size uniformity. 

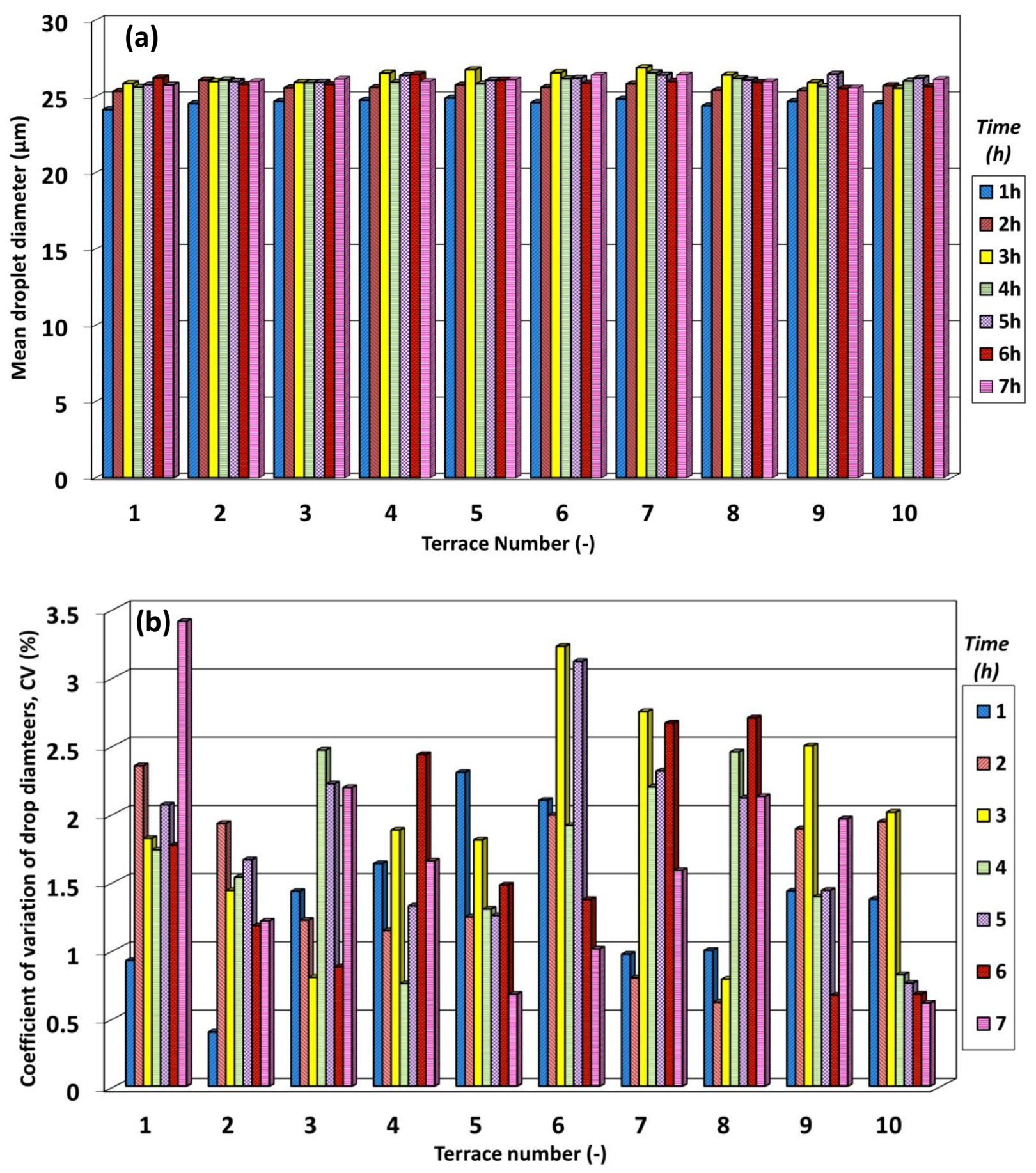

Figure 4: (a) The mean drop diameters and (b) the coefficients of variation of drop diameters at different terraces as a function of time in Chip 1. 


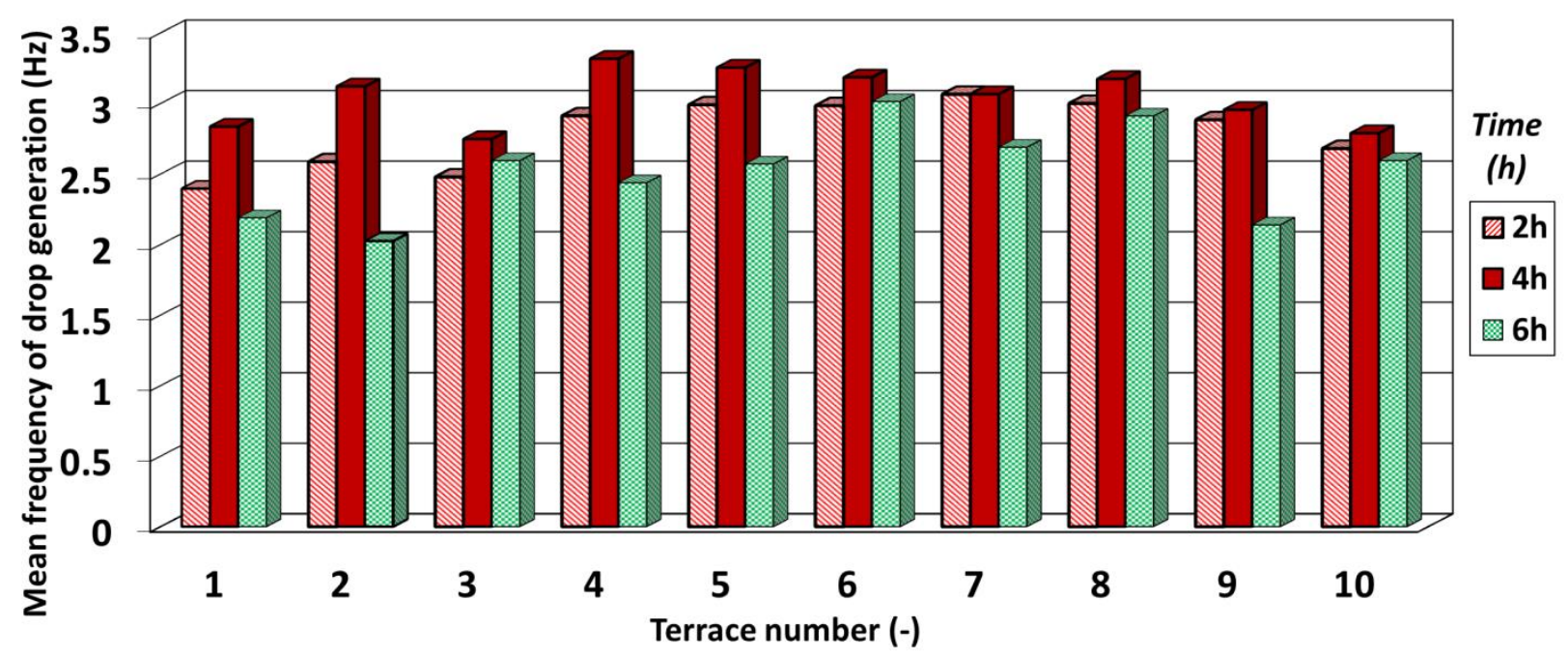

Figure 5: The mean frequencies of droplet generation at different terraces as a function of time in Chip 1. 

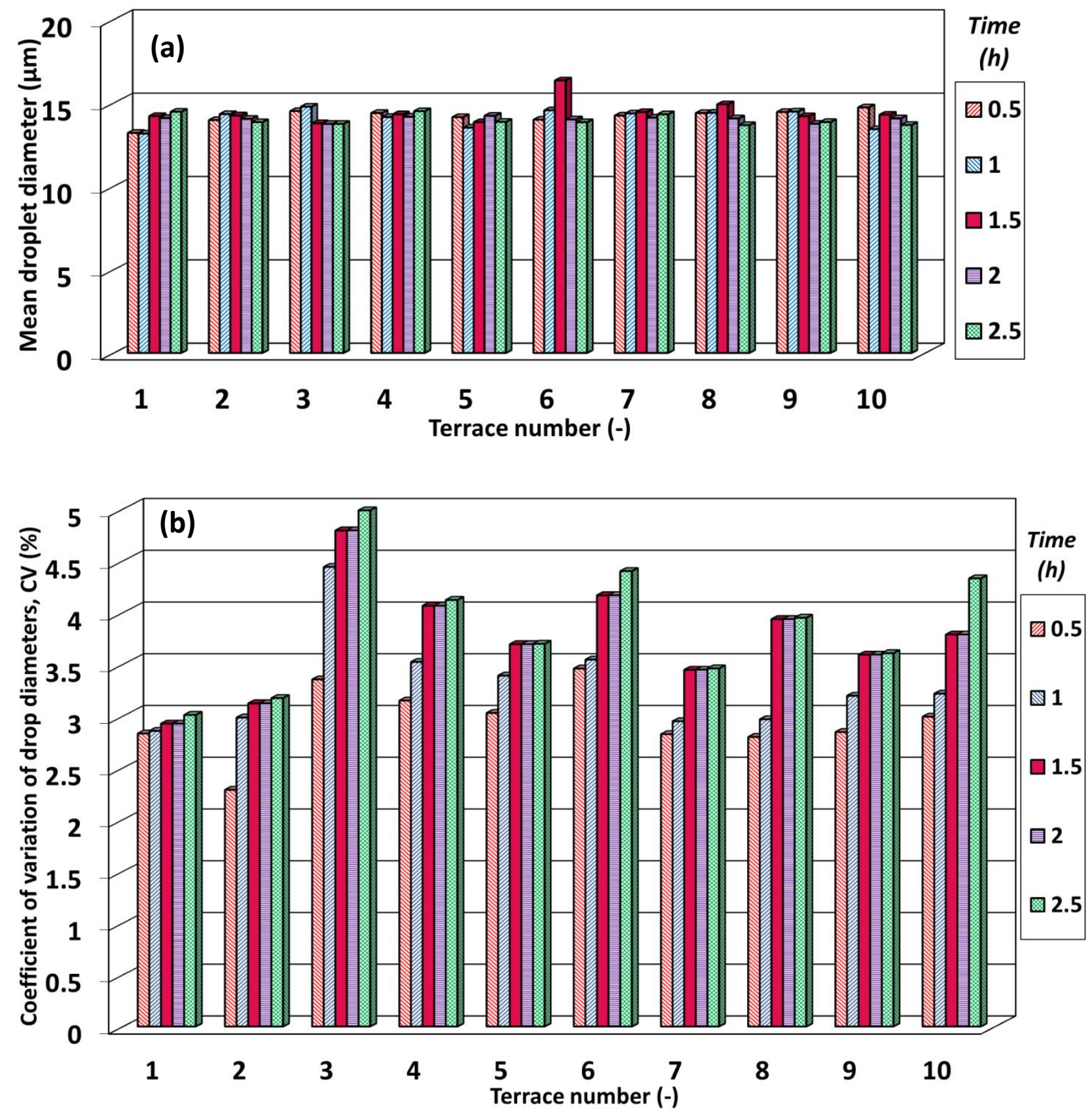

Figure 6: (a) The mean droplet diameters and (b) the coefficients of variation of droplet diameters at different terraces as a function of time for Chip 2. 


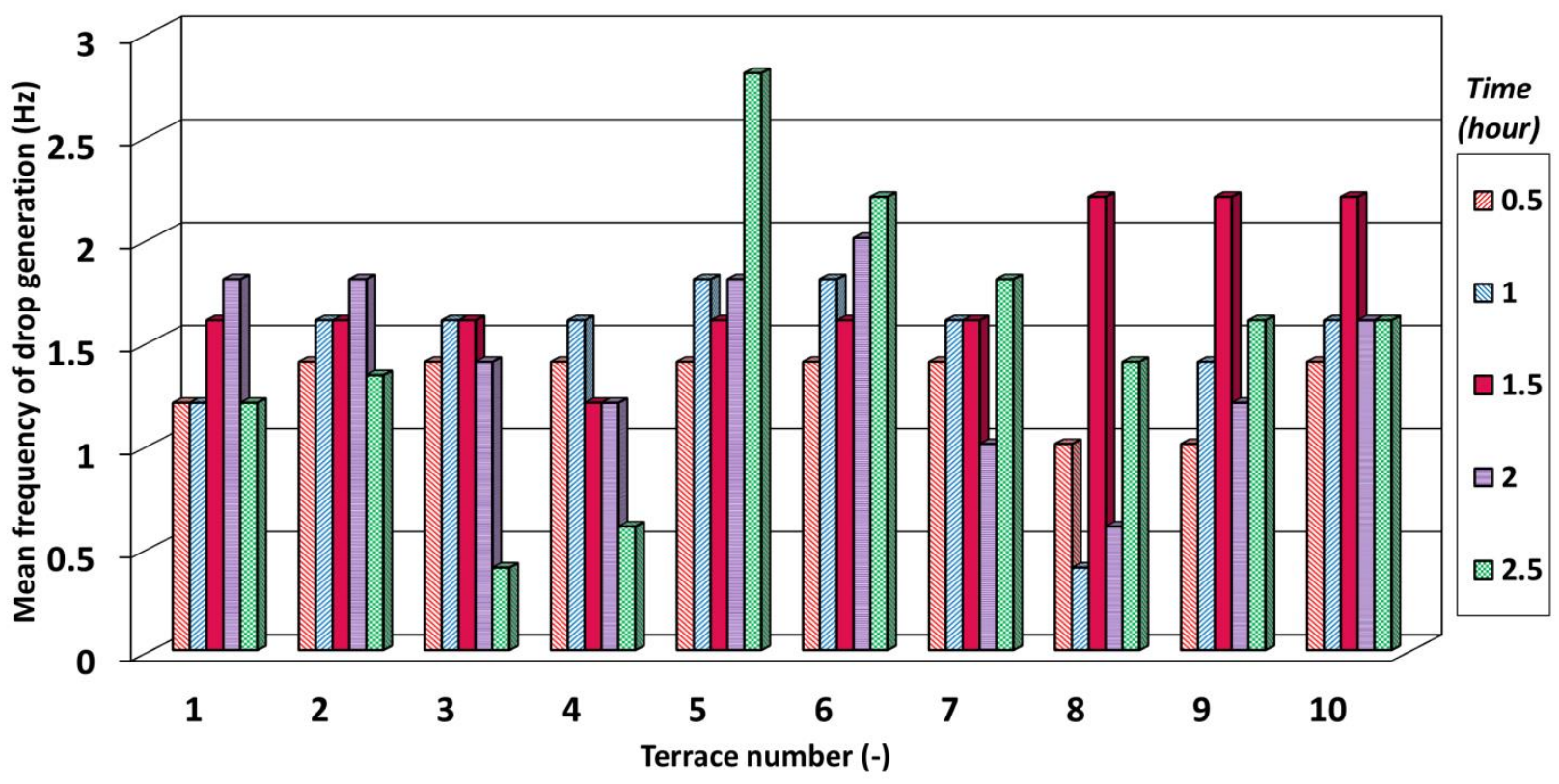

Figure 7: The mean frequencies of droplet generation at different terraces as a function of time for Chip 2. 


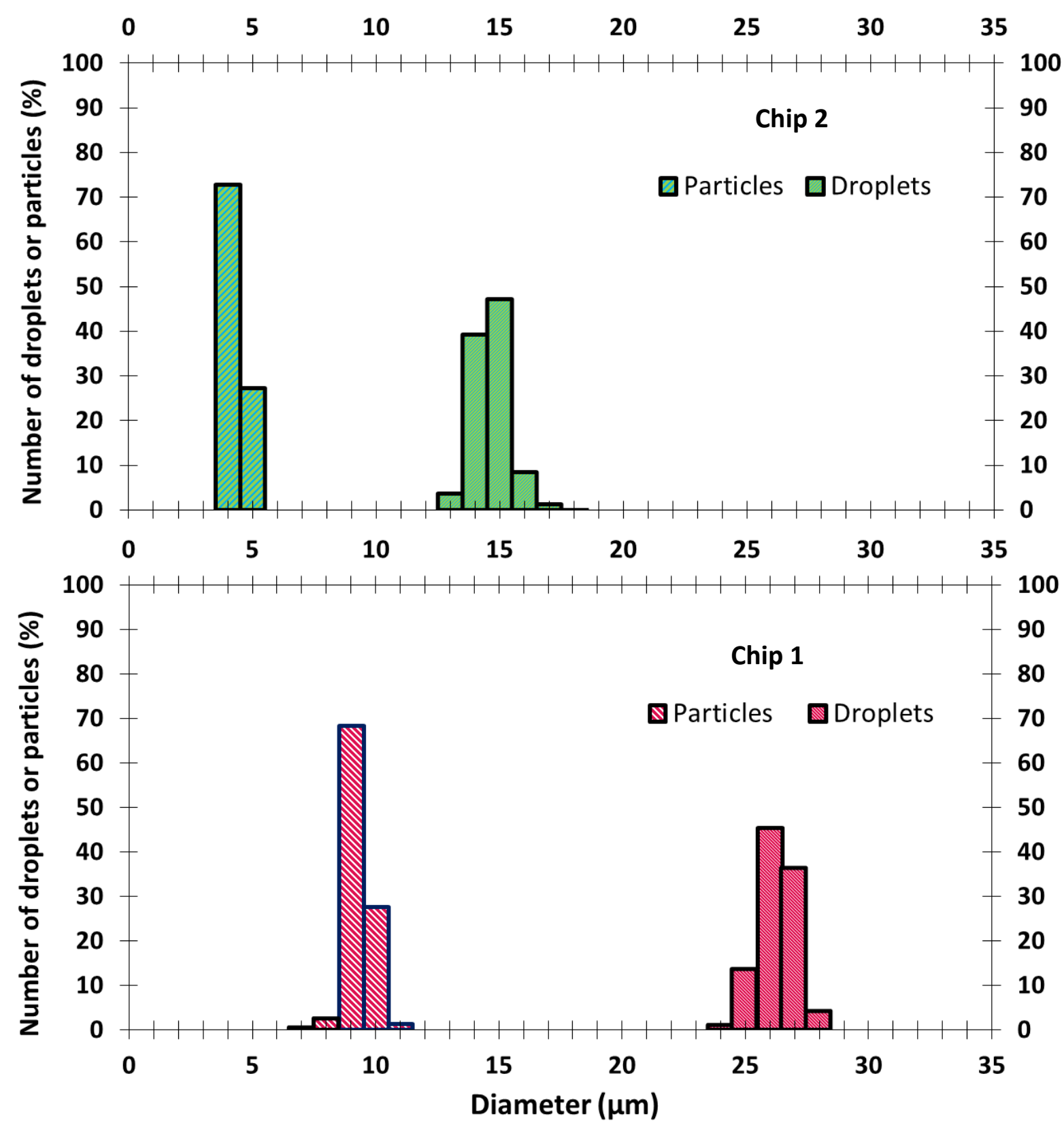

Figure 8: The particles size distributions of emulsions and polymeric particles produced using two microchannel chips. 


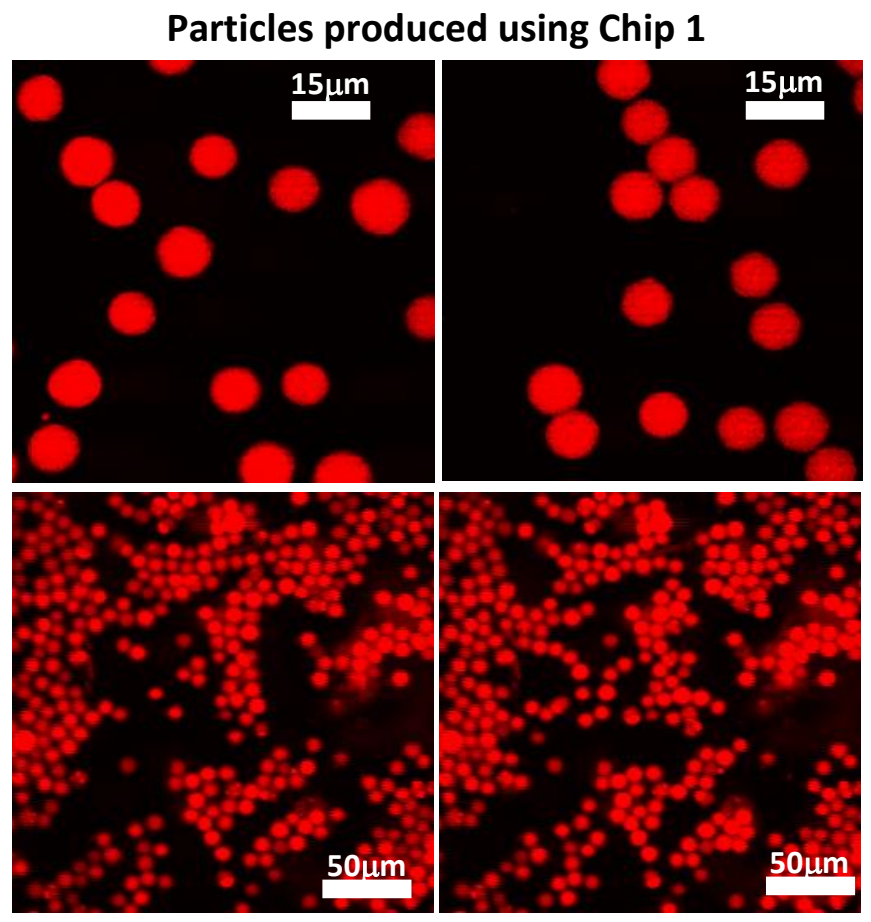

Particles produced using Chip 2

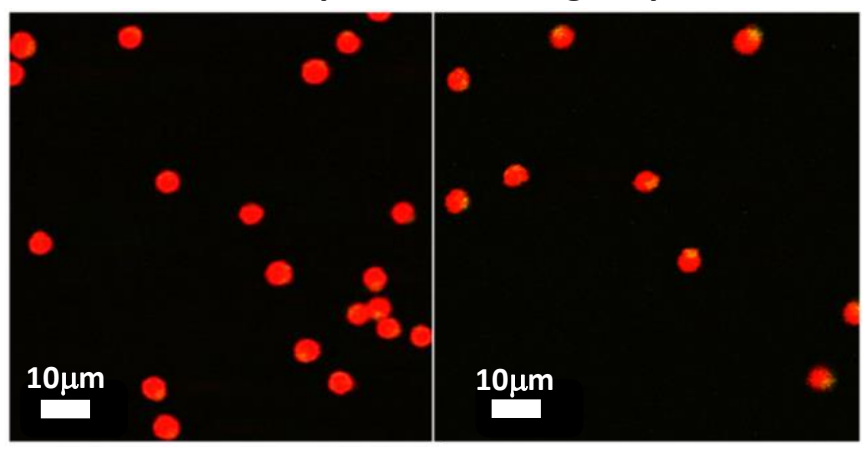

Figure 9: The CLSM images of biodegradable polymer particles produced using two different microchannel chips. 